\title{
A PRÁTICA REFLEXIVA NA FORMAÇÃO DO FILÓSOFO EDUCADOR
}

\author{
Maurilio Gadelha Aires, IFRN - Natal, Brasil
}

\section{RESUMO}

Entendendo a formação enquanto um processo de amadurecimento e desenvolvimento da pessoa humana, temos diante de nós uma tarefa que permeia toda a existência do indivíduo. Mesmo em se tratando de um aspecto dessa formação, a do filósofo educador, percebemos que a mesma, embora enfatizada na graduação, não se reduz ao tempo passado na faculdade. Dizemos isso porque embora a qualificação técnica seja imprescindível em toda área de conhecimento ela não garante sozinha uma boa prática profissional. Sendo assim, trata-se de uma tentativa de lançarmos um olhar nesse processo de formação do filósofo educador, sobretudo de fazermos um recorte em um ponto que consideramos medular que é a importância de formarmos um educador reflexivo. O objetivo de tal intento seria preparar o aluno da graduação para desde já considerar a importância de refletir sobre a sua própria prática, adotando esse processo enquanto uma atitude ética. Em se tratando da formação de um futuro professor de filosofia refletir sobre o próprio universo pedagógico deverá ser considerado como um imperativo ético que irá acompanha-lo por toda a sua prática educativa, seja como discente ou docente.

Palavras chave: reflexão, ética, formação e prática educativa.

\section{REFLEXIVE PRACTICE IN FORMING A PHILOSOPHER IN EDUCATION}

\begin{abstract}
By regarding education as a process of human maturity and development, we are faced with a task involving all the existence of the individual. Although it concerns and singles out an aspect of this education, forming a Philosopher in Education, we realize that it does not only apply to the time period spent in college, despite focusing on college graduation. We say so because in spite of the fact that technical qualification is indispensable in every field of knowledge, this qualification alone does not ensure good professional practice. Thus, it is all about an attempt to look further into this process of forming a Philosopher in Education, with an emphasis on highlighting an issue we consider substantial, which is the importance of forming a reflexive educator. We are intent on preparing the undergraduate student to take into consideration the importance of reflecting on his own practice, adopting this process as an ethical attitude. When it comes to forming a future Philosophy teacher, pondering the pedagogical universe itself ought to be considered ethically imperative and should accompany all of the educational practices of both the teachers and the students.
\end{abstract}

Keywords: reflection, ethics, education and educational practice.

\section{Introdução}

Entendendo a formação enquanto um processo de amadurecimento e desenvolvimento da pessoa humana, temos diante de nós uma tarefa que permeia toda a existência do indivíduo. Mesmo em se tratando de um aspecto dessa formação, a do filósofo educador, percebemos que essa formação, embora enfatizada na graduação, não se reduz ao tempo passado na faculdade. Porém, levando-se em consideração a vantagem do ambiente universitário, sobretudo no que diz respeito à sistematização e à intencionalidade das práticas educativas, não podemos deixar escapar a 
possibilidade de ressignificação da experiência existencial daqueles que vão passar pela academia.

A importância disso reside, de acordo com o nosso entendimento e a nossa experiência, na possibilidade de semear ideias que possam acompanhar o aluno durante toda a sua futura docência. Dizemos isso porque embora a qualificação técnica seja imprescindível em toda área de conhecimento ela não garante sozinha uma boa prática profissional. Sem a devida formação, qualquer qualificação se perde em um amontoado de técnicas despolitizadas e sem significado.

Mesmo em se tratando de um curso de Filosofia corremos o risco de estar formando bons colecionadores de citações filosóficas e nada mais. Sendo assim, trata-se de uma tentativa de lançarmos um olhar a esse processo de formação do filósofo educador, sobretudo fazendo um recorte em um ponto que consideramos medular, isto é, a importância de formarmos um educador reflexivo. O objetivo de tal intento seria preparar o aluno da graduação para desde já considerar a importância de refletir sobre a sua própria prática, adotando esse processo enquanto uma atitude ética.

Tomando como referência a própria máxima de colocar tudo à prova, reconhecidamente por todos como uma das principais características da atitude filosófica, a prática reflexiva se revestiria da atitude socrática de analisar a própria vida para buscar um sentido para ela. Em se tratando da formação de um futuro professor de Filosofia refletir sobre o próprio universo pedagógico deverá ser considerado como um imperativo ético que irá acompanhá-lo por toda a sua prática educativa, seja como discente ou docente.

\section{A reflexão como política cultural nos estabelecimentos educacionais: o papel do professor ${ }^{1}$}

Vendo a educação como parte integrante do desenvolvimento cultural da sociedade, temos a figura importantíssima do professor como sujeito comprometido com os processos educacionais que visam a um melhor aprimoramento possível da sociedade. Dentro dessa mesma linha de raciocínio, no âmbito da Filosofia da Educação, Cescon (2009) entende que a História da Filosofia está impregnada de uma preocupação pedagógica, ou seja, o problema de como ensinar da melhor maneira possível é uma preocupação que permeia a Filosofia desde os seus primórdios. Nesse sentido, a própria Pedagogia parte de um pressuposto filosófico à medida que busca analisar as ideias que fundamentam a Educação dentro de uma visão de mundo compartilhada. Sendo assim:

Pode-se afirmar que todo sistema filosófico leva, implícita ou explicitamente, a uma doutrina pedagógica e, inversamente toda pedagogia é sempre um empenho para realizar tal ideia ou tais valores que caracterizam uma determinada concepção de mundo e de vida (CESCON, 2009, p. 13).

\footnotetext{
${ }^{1}$ Uma primeira versão do texto a seguir, sofrendo algumas reformulações, encontra-se em Aires (2010).
} 
Admitirmos isso equivale a pensar a Filosofia enquanto atividade que constantemente se volta para os problemas pedagógicos da educação. Quando faz isso, a Filosofia se torna Filosofia da Educação, melhor dizendo, passa a compartilhar com outros saberes a preocupação com os processos educacionais. Dentro dessa perspectiva, toda Filosofia que se queira comprometida com o desenvolvimento da sociedade deve ter a intenção clara de servir como base de reflexão para um fazer educativo legítimo.

Partindo-se desse princípio, a característica estrutural da Filosofia enquanto atividade que se dá, sobretudo através da reflexão em torno de determinados problemas que ora lhes são colocados, deve ser uma tarefa constante de todo ato pedagógico situado dentro do âmbito escolar.

Nesses termos, o professor precisa estar ciente de que a reflexão deve ser parte integrante do seu fazer pedagógico, não só na maneira de veicular os conteúdos, mas também na sua própria maneira de encarar o seu trabalho no âmbito do seu estabelecimento de ensino. Isso é assim, pois pensamos ser difícil que um professor suscite os alunos a serem reflexivos se ele próprio não é reflexivo. "Refletir sobre a prática é consubstancial aos seres humanos" (SACRISTÁN, 1999, p. 99). Podemos perceber com isso que o caminhar pedagógico é feito, ao mesmo tempo, ensinando a aprender e aprendendo ensinando. Tudo isso sem perder de vista o olhar reflexivo durante todo o processo. Pensando dessa forma, o professor dificilmente se furtará ao exercício da reflexão; buscará intensificar e munir de maior rigor a natural característica do ser humano em pensar sobre os seus próprios pensamentos, pois: "Sem dúvida, cada pessoa reflete de modo espontâneo sobre sua prática; porém, se esse questionamento não for metódico nem regular, não vai conduzir necessariamente a tomadas de consciência nem a mudanças” (PERRENOUD, 2002, p. 43).

Podemos ver assim que a prática reflexiva sistemática faz um bem enorme, não só para os alunos, mas também é de extrema utilidade para os professores que estão coordenando e mediando os processos educacionais. Perrenoud (2002, p. 44) sintetiza:

Ele reexamina constantemente seus objetivos, seus procedimentos, suas evidências e seus saberes. Ele ingressa em um ciclo permanente de aperfeiçoamento, já que teoriza sua própria prática, seja consigo mesmo, seja com uma equipe pedagógica. O professor faz perguntas, tenta compreender seus fracassos, projeta-se no futuro; [...]. A prática reflexiva é um trabalho que, para se tornar regular, exige uma postura e uma identidade particulares.

Com efeito, podemos vislumbrar a prática reflexiva como um dos principais ganhos que alguém pode obter vivenciando a Filosofia. Memorizar conteúdos, embora seja algo importante, é uma atividade completamente destituída de um maior sentido caso esses conteúdos estejam destituídos de reflexão, pois, de que adianta alguém se apropriar de um determinado conhecimento 
sem ter uma compreensão mais ampla das consequências que aquele conhecimento poderá produzir dentro da sociedade? De que adianta sabermos alguma informação se não sabemos contextualizá$1 a^{2} ?$

É dentro dessa perspectiva que dizemos pouco adiantar o acúmulo exacerbado de conhecimentos sem que saibamos para que eles se destinam, pois, atualmente, as máquinas, por exemplo, os computadores, são muito mais capazes do que o homem para tais tarefas. É preciso saber para onde é destinado o conhecimento, quais são as suas finalidades, para não sermos ingênuos e facilmente manipuláveis pelos outros e pelas instituições.

Se o conhecimento produzido pela sociedade cresce a uma velocidade nunca antes vista, cada vez se torna mais difícil, até mesmo impossível, que alguém saiba tudo; porém, importante se faz buscarmos uma visão da totalidade para que não sejamos alienados da realidade por um torvelinho de informações desencontradas e desarticuladas. Nesse caso, o pensamento singular deve mesmo ser estimulado, pois o conhecimento também repousa na subjetividade daquele que o percebe.

Para a filosofia, hoje, a consciência subjetiva com seu efetivo poder de intervenção na atividade produtiva e na atividade social dos homens é um fato antropológico. E como tal não precisa ser provado, tanto mais que ele acompanha a espécie humana desde suas origens. Ademais, nós o exercitamos cotidianamente (SEVERINO, 1993, p. 175).

Por isso o professor reflexivo, que queira formar alunos também reflexivos, não pode ter receio de que o aluno adquira um pensamento próprio; deve mesmo fomentar isso, pois o pensamento diferente ajuda a enriquecer o próprio pensamento. Se todos pensassem de maneira igual, não haveria progresso algum no conhecimento, uma vez que não surgiria nada de novo. $\mathrm{O}$ novo surge a partir do momento em que há uma abertura para o diferente. Por isso o confronto de ideias deve mesmo ser fomentado dentro de uma perspectiva de educação reflexiva.

\section{Sócrates e o diálogo na prática reflexiva: o compromisso ético}

Sócrates pode ser considerado como um dos primeiros filósofos a estabelecer um método de ensino da Filosofia, baseado no questionamento e na problematização, aspectos tão caros a uma postura reflexiva diante da realidade.

A Filosofia no modelo socrático, a ser ensinada, pode ser vista como um compromisso de

\footnotetext{
${ }^{2}$ Esses questionamentos se inserem dentro da perspectiva de uma razão crítica versus uma instrumental. Somente com a primeira é que se pode aliar o saber fazer com o porquê de se fazer algo. Se não for assim, podemos ser exímios técnicos em determinada área, porém, ingênuos quanto ao alcance e consequência do seu fazer. Para uma crítica mais contundente á razão instrumental, cf. Adorno e Horkheimer (1985), na sua monumental obra a Dialética do esclarecimento
} 
pensar os aspectos da vida cotidiana de maneira crítica, criativa e comprometida. Nesse sentido, o caminho a ser percorrido se pauta no perguntar e no perguntar-se.

Sócrates, que havia tomado como norte a máxima de que “[...] a vida sem exame não é vida digna de um ser humano (1996, p. 46)", tinha como caminho a busca do saber por meio do processo reflexivo. Somente se interrogando e interrogando as coisas e aos outros é que alguém poderia se distanciar de meras opiniões sem fundamento seguro, pautadas tão somente numa espécie de comodidade que o pensamento cotidiano mostra por já estar pensado.

Sócrates, que gostava de frequentar as praças públicas de Athenas, preocupava-se com esse pensamento cotidiano pelo fato de ele estar impregnado de preconceitos e carente, justamente, de uma análise mais criteriosa que tornasse o homem mais digno da denominação de ser racional. Dessa maneira, podemos dizer que: "Seu papel não era promover uma teoria, ainda menos destruir, mas estimular. Fazia o seu dever de cidadão, opunha-se às ordens iníquas, mas não procurava impor-se no campo político. Estava ali para instigar” (JEANNIÈRE, 1995, p. 14).

Nesse sentido, Sócrates pensava no questionamento como um profícuo método para fazer o indivíduo refletir sobre o cotidiano e o conjunto de crenças que se formam ao seu redor. Nesse caso, trata-se mesmo de levar a dúvida às suas últimas consequências.

Colocar tudo à prova é uma das características fundamentais do conhecimento filosófico. Tal exigência nos parece ser um dos problemas estruturais de ensino de filosofia. Como ensinar, colocando tudo à prova? É justamente neste ponto que reside uma das grandes contribuições de Sócrates à docência de filosofia (SOFISTE, 2007, p. 62).

Para Sócrates, as crenças deveriam estar comprometidas com o pensamento rigoroso e crítico, sendo que a dúvida é que abriria a porta de acesso a esse conhecimento mais seguro. Duvidar de tudo, não por leviandade, mas para avaliarmos, com segurança, as bases nas quais as crenças estão assentadas. Todos têm o próprio conjunto básico de crenças. Seria até mesmo impossível alguém viver, na prática, sem abraçar um conjunto de crenças com as quais pudesse orientar a sua vida. As crenças são como uma espécie de bússola, ou para se colocar as coisas em um contexto mais moderno um tipo de GPS, pois fornecem coordenadas para que não ajamos na mais completa desorientação e incerteza. Pensamos ser oportuno o método de Sócrates $^{3}$ de colocar em dúvida as principais crenças correntes, uma vez que permite maior depuração das mesmas, permitindo uma maior confiança nas que resistirem ao bombardeio da investigação.

\footnotetext{
${ }^{3}$ Não se trata aqui de julgar Sócrates como herói ou anti-herói, mas de lançarmos luz ao método socrático dialético como forma de mediação para uma postura reflexiva que aqui nos interessa.
} 
É muito importante, nesse momento, dizermos que incentivar a reflexão nos alunos, bem ao gosto de Sócrates junto aos seus discípulos, significa que é preciso que criemos um clima propício a essa atitude. Nenhuma pessoa sensata se exporá através da menção de seus pensamentos, a menos que sinta uma mínima segurança em fazê-lo. É que, enquanto estamos calados, torna-se impossível sabermos se aquela pessoa está pensando uma tolice ou não. O que queremos pontuar com isso é que precisa existir uma atmosfera que deixe à vontade quem quer que esteja com vontade de falar. É necessário que essa pessoa não se sinta inibida, ou constrangida a não se pronunciar a respeito do que lhe vem à cabeça.

Nesse sentido, existem alguns cuidados que todo professor ou qualquer pessoa que se disponha a coordenar um diálogo tenha de observar. Nem todos se sentem estimulados a emitir a sua opinião, mesmo que convidados a isso; é preciso que se sintam bem à vontade para tanto. $\mathrm{O}$ professor precisa estar atento a esse fato e buscar elementos metodológicos que favoreçam o diálogo.

Colocar em ação o método do diálogo socrático exige um professor sensível a esses pormenores, uma vez que, a princípio, podem ser fáceis de serem observados, mas, no cotidiano, exigem um esforço concentrado, tanto por parte do professor, como por parte dos alunos, para que essas aprendizagens se deem de forma efetiva. Não podemos esquecer que em todo diálogo existe uma tensão. Quem fala gosta de estar certo do que está falando. Raríssimas vezes (e isso também exige um aprendizado) não ficamos com certo aborrecimento (embora alguns consigam disfarçar muito bem) quando somos contestados em nossos argumentos. O próprio Sócrates deixou muita gente com uma má disposição para com ele por causa de, por meio do seu método, contestar os argumentos de seu interlocutor. Portanto precisamos estar cônscios de que, pela própria natureza do diálogo, normalmente surgirão momentos de tensão que precisam ser contornados para que o mais importante seja a busca pela verdade e não o ato de ganhar a discussão em si mesma. Sem falar de que é preciso ter o cuidado para que essa fonte de construção de conhecimento, o diálogo, não sirva para criar desafetos entre as pessoas. Precisamos aceitar a natureza intrínseca de um debate e nos prepararmos da melhor maneira para ele acontecer.

Considerando que o prefixo dia indica divisão e separação (através de) e logoi (discurso, fala), o diálogo supõe a presença de um entre coisificador e diversificador. Do ponto de vista epistemológico é a pergunta que irá possibilitar a abertura deste espaço do entre. Portanto, considerar o diálogo como princípio pedagógico significa superar a lógica da afirmação, visto que a pergunta rompe as medidas da validade. Um fazer educativo que se fundamenta em tais princípios pressupõe a investigação como condição fundamental, uma vez que, nesta lógica da pergunta, em cada afirmação subjaz um momento de questionabilidade (SOFISTE, 2007, p. 96-97).

Assim, vendo no diálogo uma possibilidade ímpar para educarmos, o professor deve se 
preparar e preparar a sua turma para esse espaço do entre. Queremos dizer que o próprio diálogo ajudará nessa tarefa. Só aprenderemos a dialogar com outras pessoas exercitando a prática do diálogo. É preciso que esse legítimo método de se fazer filosofia seja mais bem trabalhado nas aulas para que o aluno vá aprendendo a lidar com o espaço do entre (entre dois discursos), da diversidade de opiniões. Ele precisa compreender que é justamente esse espaço do entre que possibilita o avanço no conhecimento, pois é o fator que permite que a investigação siga o seu curso, coisa que não aconteceria se não existisse mais nenhuma dúvida sobre o que quer que fosse. Pontos pacíficos não exigem mais que se lhes questione, que se lhes interroguem mais, uma vez que já foram “elucidados". É de suma importância que aprendamos a conviver com o espaço do entre, que fatalmente se abrirá em um diálogo, pois é da sua ocorrência que se alimentará toda a investigação.

Respeitar o espaço do entre pode ser entendido como uma construção pautada em um saber ouvir o outro, desenvolver a tolerância, entendendo que ninguém é o fiduciário da verdade. Ela é mesmo um processo que não se deixa capturar tão facilmente (se é que se deixa capturar).

Sobre a importância de saber ouvir para poder participar ativamente de um diálogo, trazemos agora uma importante contribuição. Nesse sentido, importante se torna agora transcrever essa passagem, em que cremos ter Kohan (2000, p. 108) sido bastante feliz em sua reflexão:

Consideramos, por exemplo, a prática de escutar atentamente aos outros membros da comunidade. Isto é condição do diálogo filosófico: não há diálogo se os participantes não se escutam com atenção. Ao mesmo tempo, ela cultiva a autoestima naqueles que se sentem reconhecidos pelos seus pares como portadores de uma linguagem significativa, e promove a reciprocidade e a cooperação quando quem escuta atentamente tem a sua vez de falar. Por último, isto leva a pessoa a reconhecer-se nas palavras dos demais e a estes na próxima vez. Esta prática - e todas as outras promovidas numa comunidade de questionamento e investigação tentam criar um contexto social de modo que as pessoas a ele expostas internalizem essas práticas e possam depois recriá-los em todos os âmbitos da sua experiência.

Concordamos com a citação acima, sobretudo no que tange à possibilidade de nos reconhecermos nas palavras dos outros quando lhes damos a oportunidade de falarem. É muito mais interessante quando a voz de alguém encontra eco em outras pessoas do que quando ela se perde no vazio. Por isso, além de ser de suma importância, na construção do diálogo, saber ouvir ainda proporciona a possibilidade de sermos reconhecidos como alguém que tem algo importante a falar, fomentando assim o espírito de pertencer a uma comunidade.

Nesse sentido, a experiência não cansa de mostrar quão desagradável se mostra alguém que não respeita a opinião dos outros; quando não sabe ouvir o que os outros membros do grupo têm a dizer, ou simplesmente aquele que, por vaidade, adora monopolizar a fala, não dando espaço para mais ninguém dela fazer uso. Pensamos que pessoas assim precisam experienciar mais o ouvir; é uma questão mesma de aprendizado, para que assim possam ser mais úteis na construção de uma 
comunidade investigativa. O professor precisa estar muito atento a esses pormenores quando se quiser valer do princípio pedagógico do diálogo socrático.

Prosseguindo, faz-se necessário colocarmos um elemento novo nesse argumento. Vejamos: levar uma vida reflexiva, de análise, pautada no diálogo, requer, na visão de muitos pensadores, uma vida pautada no compromisso ético. Entre eles, Freire $(1999$, p. 37) é bastante enfático e irredutível quando toca nesse ponto.

Não é possível pensar os seres humanos longe, sequer, da ética, quanto mais fora dela. Estar longe, ou pior, fora da ética, entre nós, mulheres e homens, é uma transgressão. E por isso que transformar a experiência educativa em puro treinamento técnico é amesquinhar o que há de fundamentalmente humano no exercício educativo: o seu caráter formador.

Não basta só que o professor diga aos seus alunos que eles precisam refletir acerca das suas crenças; que eles precisam saber ouvir os outros, respeitar o ponto de vista do outro; que precisam defender os seus argumentos tendo cuidado em não hostilizar o outro; mas torna-se imperioso que ele mesmo tenha uma conduta condizente com o seu discurso. O dito tem de caminhar junto com o feito. Isso é mesmo uma questão de probidade do sujeito que se utiliza de um determinado discurso.

O professor que realmente ensina, quer dizer, que trabalha os conteúdos no quadro da rigorosidade do pensar certo, nega, como falsa, a fórmula farisaica do "faça o que mando e não o que eu faço". Quem pensa certo está cansado de saber que as palavras a que falta a corporeidade do exemplo pouco ou quase nada valem. Pensar certo é fazer certo (FREIRE, 1999, p. 38).

Sempre insistimos que, mesmo na época de alunos da Graduação, a Filosofia, seja qual for o seu campo de atuação, sempre vai culminar em uma Ética. Sempre estaremos às voltas com decisões a serem tomadas que exigirão uma justificativa sobre o porquê de ser assim e não de outra forma. Toda justificativa para as ações pode simplesmente esbarrar no muro da improbidade daquele que prega algum discurso e não o pratica efetivamente. É preciso ao menos fazer um esforço para viver de acordo com o que pregamos como sendo a coisa certa.

Nesses termos, a ética parece coroar todo o aspecto da vida prática. Até mesmo a questão socrática por excelência que mostra que a vida não analisada não é digna de ser vivida provoca uma reflexão: e que tipo de vida é digna de ser vivida? Obviamente, a resposta não nasce com a pessoa, precisa ser buscada.

Ora o valor de uma vida, o que é necessário para que ela seja digna de ser vivida, não nos é dado de início, ab ovo, com nosso nascimento: ele deve ser obtido, construído, conquistado, ele reclama um trabalho de si sobre si mesmo, uma elaboração, uma transformação de si. É esse cuidado de si, a cura sui dos latinos com vistas a uma vida que valha a pena, que merece rigorosamente o nome de ética (PRADO JR., 2008, p. 61-62). 
Retomando o fio da meada, poderíamos acrescentar que, se alguém tivesse um indício de qual tipo de vida deveria ser digna de ser vivida, então, por que não viveria em conformidade com ela?

Talvez fosse por isso que Sócrates tanto quis pautar a sua vida em conformidade com a sua filosofia, pois é muito mais convincente um discurso que se sustenta na prática do que no vazio, montado apenas em palavras soltas ao vento. É como diz o ditado: a palavra convence, mas o exemplo arrasta ${ }^{4}$.

A questão da educação reflexiva deve justamente culminar em uma ética que exija a justificação do tipo de vida que se quer adotar. Não é por acaso que Sócrates é um divisor de águas na Filosofia. É por intermédio dele que há um deslocamento do eixo da Filosofia das questões cosmológica às éticas. A partir dele, tem início o período antropológico ou socrático da Filosofia. De acordo com Chauí (2004, p. 41), o período antropológico ou socrático é assim chamado pela importância que Sócrates exerceu no pensamento da sua época. "Propunha que, antes de querer conhecer a natureza e antes de querer persuadir os outros, cada um deveria, primeiro e antes de tudo, conhecer-se a si mesmo [...]”. E mais adiante, a autora finaliza:

Por fazer do autoconhecimento ou do conhecimento que os homens têm de si mesmos a condição de todos os outros conhecimentos verdadeiros é que se diz que o período socrático é antropológico, isto é, voltado para o conhecimento do homem (em grego, ántropos), particularmente de seu espírito e de sua capacidade para conhecer a verdade (CHAUÍ, 2004, p. 41).

Sendo assim, não é apenas o âmbito do racional que deve ser vislumbrado com a prática da Filosofia, mas a questão ética também é de suma importância caso se queira contemplar "a totalidade da alma humana", justamente na sua dimensão mais humana, que é a existência ética. "Para Sócrates, a verdadeira sabedoria é o conhecimento perfeito acerca de assuntos éticos, acerca de como se deve viver" (GOTTLIEB, 1999, p. 19). Essas são questões éticas que sempre sensibilizarão o homem.

Assim sendo, o exercício da filosofia não é apenas um aprimoramento do intelecto para que seja utilizado em discussões acaloradas, sem nenhuma contribuição efetiva à vida, mas uma experiência vital, algo que transforme efetivamente a vida daqueles que pratiquem a experiência do filosofar, não só em bases racionalistas discursivas, mas, acima de tudo, que toque com força as questões existenciais mais delicadas com as quais convivemos.

É interessante notarmos que a experiência vital reivindicada pelos filósofos da antiguidade

\footnotetext{
4"Verba movent, exempla trahunt".
} 
encontre eco em nossos dias, principalmente quando vemos educadores como Paulo Freire, para quem tal experiência seria tanto mais significativa, quanto estivesse permeada de curiosidade, enquanto inquietação indagadora pela busca do esclarecimento.

Como manifestação presente à experiência vital, a curiosidade humana vem sendo histórica e socialmente construída e reconstruída. Precisamente porque a promoção da ingenuidade para a criticidade não se dá automaticamente, uma das tarefas precípuas da prática educativo-progressista é exatamente o desenvolvimento da curiosidade crítica, insatisfeita, indócil (FREIRE, 1999, p. 35-36).

Justamente, para que essa curiosidade pudesse avançar criticamente e transformar-se em uma curiosidade epistemológica, seria preciso um compromisso ético para que fossem evitadas transgressões de uma conduta moralmente correta e responsável. "É no domínio da decisão, da avaliação, da liberdade, da ruptura, da opção, que se instaura a necessidade da ética e se impõe a responsabilidade. A ética se torna inevitável e sua transgressão possível um desvalor, jamais uma virtude" (FREIRE, 1999, p. 20).

Nunca é demais dizermos que, em se tratando de uma totalidade da alma, as questões do cotidiano servem, sim, de referência. A filosofia é um processo que enseja a análise de assuntos do cotidiano e a forma como abordá-los. Nesse sentido, a reflexão filosófica funciona como uma forma de depuração, muitas vezes dolorosa, das teorias de mundo erigidas no dia a dia e no âmago das relações sociais.

Nesse sentido, o que pode uma educação reflexiva nos dias de hoje? Pensamos ser essa uma boa questão para continuarmos com a análise acerca da formação do Filósofo Educador em moldes reflexivos.

\section{O imperativo de uma conduta reflexiva nos dias atuais: em busca de uma formação para um futuro professor reflexivo}

Hoje em dia, muito se debate acerca de uma educação problematizadora e crítica, da importância de um ensino que suscite, no professor e no aluno, a reflexão (OBIOLS, 2002; SHARP, 2000; SANTIAGO, 2000; REED, 2000; KOHAN, 2000; CERLETTI, 2005; SEVERINO, 2005; KOHAN, 2005; GUIDO, 2005; SACRISTAN, 1999; GAUTHIER, 1998; PERRENOUD, 2002; TARDIF, 2008; MORIN, 2004; WATANABE, 2006; GHEDIN, 2008). Gostaríamos de pontuar, nesse momento que, para estimular nos alunos uma atitude reflexiva, o professor, ele próprio, precisa estar habituado ao exercício da reflexão para, na pior das hipóteses, saber mediar os movimentos reflexivos dos seus alunos quando esses acontecerem. Consideramos uma contradição o professor querer ensinar o aluno a ser reflexivo sem que ele próprio tenha o hábito de refletir 
sobre as questões.

Sobre a questão do significado da terminologia hábito temos de fazer algumas considerações: primeiramente, vemos certa limitação quanto ao seu entendimento nos dias atuais, sendo que, muitas vezes, essa palavra acaba sendo mal compreendida por comportar apenas o seu significado negativo, geralmente associado a um fazer totalmente destituído de reflexão; ou seja, agindo pelo hábito se estaria apenas movido por automatismos; além disso, o hábito teria a característica de inviabilizar os processos mais simbólicos e metacognitivos no homem; só para citar alguns significados negativos atribuídos ao hábito.

É possível pensarmos por outra perspectiva, pois o seu significado permite essa abertura. Ao longo da história da filosofia, o tema do hábito recebeu um tratamento mais digno e coerente. Por exemplo, Aristóteles (1996) vê o hábito como algo possível de ser modificado. Uma coisa que já tem uma natureza pré-estabelecida não pode se dar de uma outra forma, pois contrariaria a sua disposição natural. Somente podemos modificar uma coisa se pudermos habituá-la a uma mudança de comportamento; jamais poderíamos mudar algo que existisse por natureza, ou necessariamente. O próprio Aristóteles é bastante enfático:

[...] a pedra, que por natureza se move para baixo, não pode ser habituada a mover-se para cima; tampouco o fogo pode ser habituado a mover-se para baixo, nem qualquer outra coisa que por natureza se comporta de certa maneira pode ser habituada a comportar-se de maneira diferente (1996, p. 137).

O hábito acaba sendo algo que favorece às pessoas, uma vez que, graças ao fato de se poderem cultivar diferentes hábitos, podemos modificar o próprio comportamento, ou seja, podemos sair de um comportamento que julgamos inadequado para um que julgamos adequado. Se o comportamento já fosse estabelecido por natureza, como o da pedra e do fogo, por exemplo, jamais alguém poderia efetuar qualquer modificação nele. Assim, graças ao hábito as pessoas podem mudar e transcenderem a condição de apenas seres naturais para também serem culturais, a despeito da cultura ser uma forma de hábito coletivo e socialmente partilhado.

Numa perspectiva mais contemporânea, Perrenoud (2002) afirma que a prática reflexiva pode se tornar um hábito, assim como um jogging, caso seja transformada em um modus vivendi integrado à vida cotidiana.

Sendo assim, de modo paradoxal, a formação na prática reflexiva pode transformar a reflexão em rotina que, apesar de não ser relaxante, pode ser experimentada sem esgotamento e sem estresse. Um dos fatores, o mais fácil de ser trabalhado, tem relação com o domínio dos recursos intelectuais da reflexão: hábito de duvidar, de se surpreender, de fazer perguntas, de ler, de anotar algumas reflexões, de debater, 
de refletir em voz alta. Todas essas atividades são métodos para dividir os problemas em séries, para dividir as tarefas, encontrar informações e obter ajuda (PERRENOUD, 2002, p. 66).

Podemos observar na citação de Perrenoud que ele trata a questão do hábito enquanto algo positivo, observando a sua sedimentação através de esquemas que podem ser muito úteis no auxílio da prática reflexiva. Para ele, a questão do hábito é mesmo crucial para uma melhor fixação de um comportamento reflexivo genuíno. Não conseguimos ver, nesse caso, como uma rotina de analisar cuidadosamente os fatos do cotidiano poderia ser prejudicial à formação de um indivíduo crítico. Ademais, todos os hábitos elencados por ele, se forem realmente incorporados, tornando-se uma rotina, constituir-se-ão em excelentes meios de alguém se tornar investigador por excelência.

Gostaríamos agora de tentar imaginar um ambiente onde o hábito da reflexão pudesse ser suscitado com frequência. Se conseguíssemos construir uma atmosfera que estimulasse a reflexão constantemente nas aulas, estaríamos criando um ambiente profícuo ao aprendizado problematizador, crítico e criativo. Um ambiente assim deveria ser agradável para que as pessoas se sentissem à vontade para exporem as suas opiniões. Para tanto, elas precisariam ser estimuladas, na forma de uma estratégia, que lhes proporcionassem prazer em irem construindo as suas ideias. $\mathrm{O}$ contexto em que esse prazer pudesse ser buscado seria um clima de ludicidade na forma de se vivenciar a aula, ou seja, o seu desenvolvimento teria que se balizar numa atmosfera que contemplasse também o fenômeno do lúdico. "A relação escolar com o saber, quando é séria e dependente, sem distanciamento crítico e sem espírito lúdico, não é favorável a uma prática reflexiva, a qual exige que se pense por si mesmo e que se utilizem os saberes de forma pragmática e ousada" (PERRENOUD, 2002, p. 67).

Ao partirmos desses princípios, de que o espírito crítico e reflexivo pode ser construído numa perspectiva de hábito, ou seja, de que, sem constrangimento algum, podemos e devemos reforçar nos alunos uma postura reflexiva diante da realidade; de que essa postura seja fixada o mais profundamente possível, seja impregnada em todos, faça parte do cotidiano das pessoas; de que tenhamos o hábito de questionar sempre que ocorra algum incômodo com alguma coisa dita por outrem, na sala de aula, lida em algum texto, ouvida em algum outro lugar, ou até mesmo pronunciada pela própria pessoa sem muita reflexão; se assim for, pensamos estar trilhando uma senda mais propícia à busca da verdade enquanto ideal da própria Filosofia.

Perrenoud (2002) menciona que as ações possuem uma espécie de "memória" que permite estruturar o vivido na forma de conhecimento. O processo funciona mais ou menos assim:

Beber um copo d'água não é um gesto inserido no patrimônio genético. Um recémnascido não sabe fazer isso. Ao crescer, constrói e estabiliza um esquema que lhe permite, pouco a pouco, beber com qualquer tipo de copos. O esquema não é específico para um copo em particular; porém, não permite que se beba, sem alguma adaptação notável, de uma torneira, de uma garrafa, de uma caixa ou de 
outro recipiente de forma insólita. Um esquema pode ser adaptado a um leque mais amplo de situações. Quando essa adaptação se repete, ela é estabilizada e há uma diferenciação do esquema. Durante toda a vida, novos esquemas nunca deixam de se desenvolver, de se diferenciar e de se coordenar uns aos outros (PERRENOUD, 2002, p. 81).

Utilizamo-nos dessa longa citação para enfatizar que o hábito tem uma importância primordial no processo de aprendizagem humana. Se não fosse pelo hábito, jamais se poderiam criar esses esquemas de aprendizagem e eles jamais se formariam nas pessoas. Tudo seria sempre novidade. Entretanto sabemos que os acontecimentos nunca são totalmente iguais. Porém, colhendo semelhanças entre os eventos diferentes, vamos, através do hábito, criando associações entre as várias causas que se sucedem, construindo, dessa forma, os esquemas facilitadores e, sem eles, jamais poderíamos ampliar o cabedal de conhecimentos acerca do mundo.

Por isso, seria por demais importante se, na prática pedagógica da maioria dos professores, houvesse a ocorrência de uma metodologia que estimulasse a instalação desses esquemas reflexivos; e tornasse a reflexão uma coisa mais natural e recorrente na conduta dos alunos. "Talvez devêssemos concluir, então, que a prática reflexiva se aprende mediante um treinamento regular e intensivo sem que ela mesma seja objeto de importantes ajustes metacognitivos" (PERRENOUD, 2002, p. 87). Sendo, então, o hábito um conjunto de atitudes interiorizadas, a aprendizagem desse esquema de organização de condutas é desenvolvida a partir dos atos e das formas de interação com o mundo.

Cremos que, no dia em que se tiver contribuído mais incisivamente para a formação desse hábito reflexivo, deparar-nos-emos com uma questão que causará certo incômodo: por que não estimulamos, nos alunos e em nós mesmos, esse hábito de refletir sobre tudo bem antes? Mas, pelo menos, ficaremos mais tranquilos pelo fato de que nunca mais abandonaremos esse ideal socrático de se manter sempre vigilante diante das crenças que formam o tecido social no qual estamos imersos, adotando a atitude de interrogar e a de interrogarmo-nos diante da complexidade da existência.

A reflexão é um método para alcançar níveis mais altos de racionalidade na prática e nas próprias crenças, um processo que a educação deve consolidar como disposição permanente e aberta para submeter à elaboração e revisão constantes daquilo que 'o mundo parece ser' e as contradições existentes entre algumas de nossas crenças (SACRISTÁN, 1999, p. 105).

Com efeito, para que o professor possa, cada vez mais, aprender com a própria prática, é necessário que ele esteja sempre disposto a reorientá-la, corrigindo os erros que inevitavelmente ocorrerão vez ou outra, sempre com o desejo de melhoria contínua. Pensamos que a postura reflexiva, diante da própria prática pedagógica, é um caminho viável para a obtenção do 
aperfeiçoamento do educador.

Por isso, para finalizar, gostaríamos de dizer que um ensino reflexivo de Filosofia deve ser um dos principais componentes na formação de um filósofo educador; ele deve ter a pretensão de estimular o pensamento e, até mesmo, o surgimento de pensadores, não enquanto intelectuais de uma elite de pensadores (podem até surgir alguns, o que seria ótimo), mas enquanto pessoas que buscam uma compreensão sistemática da sua realidade, da sua história e do seu próprio modo de ver o mundo. Nestes termos, o pensar por si mesmo deve ser a própria motivação para um pensar reflexivo, para que o sujeito possa se ver como alguém apto a dar a sua contribuição no processo de desenvolvimento cultural da sociedade.

\section{Referências}

ADORNO, T. W; HORKHEIMER, M. Dialética do esclarecimento: fragmentos filosóficos. Tradução de Guido Antônio de Almeida. Rio de Janeiro: Jorge Zahar Editor, 1985.

AIRES, M. G. O ensino de filosofia no ensino médio mediado pela literatura sartriana. 2010. 259f. Tese (Doutorado em Educação) - Centro de Ciências Sociais Aplicadas, Universidade Federal do Rio Grande do Norte, Natal.

CESCON, E. A filosofia e a educação. In: CESCON, Everaldo; NORDARI, Paulo César. Temas de filosofia da educação. Caxias do Sul: EDUCS, 2009.

CERLETTI, A. A. Filosofia/educação: os desafios políticos de uma relação complicada. In: KOHAN, Walter (org.). Ensino de filosofia - perspectivas. Belo Horizonte: Autêntica, 2005.

CHAUÍ, M. Convite à filosofia. 13. ed. São Paulo: Editora Ática, 2004.

FREIRE, P. Pedagogia da autonomia: saberes necessários à prática educativa. 11. ed. São Paulo: Paz e Terra, 1999. (Coleção leitura).

GAUTHIER, C. et. al. Por uma teoria da pedagogia: pesquisas contemporâneas sobre o saber docente. Tradução de Francisco Pereira. Ijuí: Ed. Unijuí, 1998. (Coleção Fronteiras da Educação).

GHEDIN, E. Ensino de filosofia no ensino médio. São Paulo: Cortez, 2008. (Coleção Docência em Formação. Série Ensino Médio).

GUIDO, H. A. O. A concepção filosófica de infância na modernidade: a contribuição humanista e racionalista. In: KOHAN, Walter (org.). Ensino de filosofia - perspectivas. Belo Horizonte: Autêntica, 2005.

GOTTLIEB, A. Sócrates: o mártir da filosofia. Tradução de Irley Fernandes Franco. São Paulo: UNESP, 1999. (Coleção grandes filósofos).

JEANNIÉRE, A. Platão. Tradução de Lucy Magalhães. Rio de Janeiro: Zahar, 1995. (Biblioteca de filosofia).

KOHAN, W O. Fundamentos para compreender e pensar a tentativa de Matthew Lipman. In: 
KOHAN, W.; WENSCH, A. M. (orgs.). Filosofia para crianças: a tentativa pioneira de Matthew Lipman. 3. ed. Petrópolis: Vozes, 2000. (Série Filosofia na Escola).

. Uma educação da filosofia através da infância. In. KOHAN, Walter (org.). Ensino de filosofia - perspectivas. Belo Horizonte: Autêntica, 2005.

MORIN, E. A cabeça bem-feita: repensar a reforma, reformar o pensamento. 9. ed. Tradução de Eloá Jacobina. Rio de Janeiro: Bertrand Brasil, 2004.

OBIOLS, G. Uma introdução ao ensino da filosofia. Tradução de Sílvio Gallo. Ijuí; Editora Unijuí, 2002. (coleção filosofia e ensino).

PERRENOUD, P. A prática reflexiva no ofício de professor: profissionalização e razão pedagógica. Tradução de Cláudia Schilling. Porto Alegre: Artmed, 2002.

PLATÃO. Defesa de Sócrates. Tradução de Jaime Bruna. Seleção de textos de José Américo Motta Pessanha. São Paulo: Nova Cultural, 1996. (Coleção os pensadores).

PRADO JR. P. W. Aprender a viver - Wittgenstein e o "não-curso" de filosofia. In: BORBA, Siomara; KOHAN, Walter (orgs.). Filosofia, aprendizagem, experiência. Belo Horizonte: Autêntica Editora, 2008.

REED, R. Tempos perdidos, tempos recuperados. Tradução de Jaime A. Clasen. In: KOHAN,Walter; WENSCH, Ana Míriam (orgs.). Filosofia para crianças: a tentativa pioneira de Matthew Lipman. 3. ed. Petrópolis: Vozes, 2000. (Série Filosofia na Escola).

SACRISTÁN, J. G. Poderes instáveis em educação. Tradução de Beatriz Affonso Neves. Porto Alegre: Artes Médicas, 1999.

SANTIAGO, G. A história das histórias. Tradução de Jaime A. Clasen. In: KOHAN,Walter; WENSCH, Ana Míriam (orgs.). Filosofia para crianças: a tentativa pioneira de Matthew Lipman. 3. ed. Petrópolis: Vozes, 2000. (Série Filosofia na Escola).

SEVERINO, A. J. A filosofia na formação do jovem e a ressignificação de sua experiência existencial. In. KOHAN, Walter (org.). Ensino de filosofia - perspectivas. Belo Horizonte: Autêntica, 2005.

Filosofia. São Paulo: Cortez, 1993. (Coleção Magistério $2^{\circ}$ Grau - Série Formação Geral).

SHARP, A. M. Prólogo. In: KOHAN,Walter; WENSCH, Ana Míriam (orgs.). Filosofia para crianças: a tentativa pioneira de Matthew Lipman. 3. ed. Petrópolis: Vozes, 2000. (Série Filosofia na Escola).

SOFISTE, J. G. Sócrates e o ensino da filosofia: investigação dialógica: uma pedagogia para a docência de filosofia. Petrópolis: Vozes, 2007.

WATANABE, L. A. Platão, por mitos e hipóteses. 2. ed. São Paulo: Moderna, 2006. (Coleção $\log$ os). 